\title{
The default mode network and social understanding of others: what do brain connectivity studies tell us
}

\author{
Wanqing $\mathrm{Li}^{1,2}$, Xiaoqin Mai ${ }^{3 *}$ and Chao Liu ${ }^{1,2 *}$ \\ 1 State Key Laboratory of Cognitive Neuroscience and Learning and IDG/McGovern Institute for Brain Research, Beijing Normal University, Beijing, China \\ ${ }^{2}$ Center for Collaboration and Innovation in Brain and Learning Sciences, Beijing Normal University, Beijing, China \\ ${ }^{3}$ Department of Psychology, Renmin University of China, Beijing, China
}

\section{Edited by:}

Hauke R. Heekeren, Freie

Universität Berlin, Germany

\section{Reviewed by:}

Xi-Nian Zuo, Chinese Academy of

Sciences, China

Qingbao Yu, The Mind Research

Network, USA

Joe Moran, Natick Soldier Research

and Development Center, USA

\section{*Correspondence:}

Xiaoqin Mai, Department of

Psychology, Renmin University of

China, No. 59, Zhongguancun Street,

Haidian District, Beijing 100872,

China

e-mail:maixq@ruc.edu.cn;

Chao Liu, State Key Laboratory of

Cognitive Neuroscience and

Learning, Beijing Normal University,

No. 19, Xinjiekouwai Street, Haidian

District, Beijing 100875, China

e-mail: liuchao@bnu.edu.cn
The Default Mode Network (DMN) has been found to be involved in various domains of cognitive and social processing. The present article will review brain connectivity results related to the DMN in the fields of social understanding of others: emotion perception, empathy, theory of mind, and morality. Most of the reviewed studies focused on healthy subjects with no neurological and psychiatric disease, but some studies on patients with autism and psychopathy will also be discussed. Common results show that the medial prefrontal cortex (MPFC) plays a key role in the social understanding of others, and the subregions of the MPFC contribute differently to this function according to their roles in different subsystems of the DMN. At the bottom, the ventral MPFC in the medial temporal lobe (MTL) subsystem and its connections with emotion regions are mainly associated with emotion engagement during social interactions. Above, the anterior MPFC (aMPFC) in the cortical midline structures (CMS) and its connections with posterior and anterior cingulate cortex contribute mostly to making self-other distinctions. At the top, the dorsal MPFC (dMPFC) in the dMPFC subsystem and its connection with the temporo-parietal junction (TPJ) are primarily related to the understanding of other's mental states. As behaviors become more complex, the related regions in frontal cortex are located higher. This reflects the transfer of information processing from automatic to cognitive processes with the increase of the complexity of social interaction. Besides the MPFC and TPJ, the connectivities of posterior cingulate cortex (PCC) also show some changes during tasks from the four social fields. These results indicate that the DMN is indispensable in the social understanding of others.

Keywords: default mode network, social cognition, brain connectivity, morality, theory of mind, empathy

\section{INTRODUCTION \\ THE DEFAULT MODE NETWORK AND SOCIAL UNDERSTANDING OF OTHERS}

Human beings are social animals that have a tendency to interpret stimuli according to their possible social relevance, and spend a huge amount of time assessing one's own and other's social relationships and positions by engaging in activities such as thinking about oneself and others and exchanging those thoughts during the whole of life (Schilbach et al., 2008). Dunbar and coleagues suggested a "social brain hypothesis," which deemed that the large brains observed in primates reflected the computational demands of the complex social systems that characterized the order of their members (Dunbar, 1993).

In the past two decades, the social brain of human has been intensively studied in several different domains: (1) understanding others, (2) understanding oneself, (3) controlling oneself, and (4) the processes that occur at the interface of self and others (Lieberman, 2007). However, in the strictest sense, social cognition is about understanding of other people, including their emotional, mental, psychological status, and behaviors (Lieberman, 2007). Increasing studies have shown that regions of the default mode network (DMN) largely activate in tasks requiring participants to understand and interact with others, such as perceiving and interpreting other's emotion status, showing empathy to other people, inferring other's belief and intention, and performing moral judgments on other's behavior (Schilbach et al., 2008; Laird et al., 2011). Besides overlaps with the DMN, the large scale brain networks for social domains also contain several regions outside the DMN, since these social behaviors usually comprise extensive cognitive processes such as obtaining, retrieving, and processing information about the lives, relationships, and mental states of others (Mars et al., 2012).

In the present article we will review results related to the DMN in the field of social understanding of others using brain connectivity methods. Several important fields of social behavior, emotion perception, empathy, theory of mind (ToM, or mentalizing), and morality, will be summarized for both healthy subjects and patients with autism, psychopathy and schizophrenia (see Table 1). The existing results were organized through two aspects. The first one is how the regions within the DMN interact with each other when people perform those social tasks, and the second one is how the DMN interacts with other distributed brain systems that contribute to the process of social cognition of others. Possible future directions will be discussed at the end. 
Table 1 | Brain connectivity studies on the social understanding of others.

\begin{tabular}{llllll}
\hline Study & Paradigm & Method & $\begin{array}{l}\text { Connectivity } \\
\text { within the DMN }\end{array}$ & $\begin{array}{l}\text { Connectivity between } \\
\text { DMN and other regions }\end{array}$ & $\begin{array}{c}\text { Number of subjects } \\
\text { Results }\end{array}$ \\
\hline
\end{tabular}

\section{EMOTION PERCEPTION}

Etkin et al., $2006 \quad$ Emotional stroop task
$\mathrm{EC}, \mathrm{PPI}$

voxel-wise DCM rostral

ACC-amygdala
19 amygdala during high conflict, the strength predicted successful conflict resolution

\begin{tabular}{llll}
\hline $\begin{array}{l}\text { Passamonti } \\
\text { et al., } 2008\end{array}$ & $\begin{array}{l}\text { Emotional faces } \\
\text { gender decision }\end{array}$ & $\begin{array}{l}\text { EC, PPI, } \\
\text { voxel-wise DCM }\end{array}$ & vACC-amygdala \\
\hline Das et al., 2005 & Fear perception & FC, PPI, \\
seed-based & & $\begin{array}{l}\text { vACC, and dACC } \\
\text { with thalamus- } \\
\end{array}$ \\
& & $\begin{array}{l}\text { sensory cortex } \\
\text { pathway, and } \\
\text { thalamus- } \\
\end{array}$ & $\begin{array}{l}\text { amygdala } \\
\text { pathway }\end{array}$
\end{tabular}

21 EC from vACC to amygdala negatively correlated to reward-drive score

\begin{tabular}{lll}
\hline Cremers et al., & Emotional faces & FC, PPI, \\
2010 & gender decision & voxel-wise
\end{tabular}

\section{dMPFC-}

amygdala

ACC-amygdala
28

Positive modulation from $\mathrm{dACC}$ and negative relationship from $v A C C$ on thalamus-sensory cortex pathway; both dorsal and vACC had inverse interaction with thalamus-amygdala pathway

\begin{tabular}{|c|c|c|c|c|c|c|}
\hline & & & & & & $\begin{array}{l}\text { amygdala for angry and } \\
\text { fearful faces, and } \\
\text { negatively correlated with } \\
\text { FC of ACC-left amygdala } \\
\text { for angry, fearful, and sad } \\
\text { faces }\end{array}$ \\
\hline $\begin{array}{l}\text { Satterthwaite } \\
\text { al., } 2011\end{array}$ & $\begin{array}{l}\text { Emotion } \\
\text { identification }\end{array}$ & $\begin{array}{l}\text { FC, PPI, } \\
\text { voxel-wise }\end{array}$ & & $\begin{array}{l}\text { Medial } \\
\text { OFC-amygdala, } \\
\text { MPFC-amygdala }\end{array}$ & 39 & $\begin{array}{l}\text { Positive FC of medial } \\
\text { OFC-amygdala, and } \\
\text { negative FC of } \\
\text { MPFC-amygdala during } \\
\text { task }\end{array}$ \\
\hline leinhans et al., & $\begin{array}{l}\text { Face } \\
\text { identification }\end{array}$ & FC, seed-based & & PCC-FFA & 47 (24 autistic) & $\downarrow F C$ in ASD group \\
\hline $\begin{array}{l}\text { Rudie et al., } \\
012\end{array}$ & $\begin{array}{l}\text { View emotional } \\
\text { face expressions }\end{array}$ & FC, seed-based & & vMPFC-rIFGpo & 47 (23 autistic) & $\downarrow$ negative $\mathrm{FC}$ in ASD group \\
\hline \multicolumn{7}{|l|}{ EMPATHY } \\
\hline $\begin{array}{l}\text { Decety et al., } \\
008\end{array}$ & $\begin{array}{l}\text { View pain } \\
\text { scenarios }\end{array}$ & $\begin{array}{l}\text { EC, PPI, } \\
\text { voxel-wise }\end{array}$ & $\begin{array}{l}\text { Medial OFC-right } \\
\text { TPJ, } \\
\text { ParaCC-right TPJ }\end{array}$ & $\begin{array}{l}\text { Medial } \\
\text { OFC-anterior } \\
\text { IPS, precentral } \\
\text { sulcus, and } \\
\text { anterior MCC; } \\
\text { ParaCC-anterior } \\
\text { IPS, and } \\
\text { precentral sulcus }\end{array}$ & 17 & $\begin{array}{l}\uparrow E C \text { during condition of } \\
\text { pain which was caused } \\
\text { intentionally compared to } \\
\text { pain which occurred } \\
\text { accidentally }\end{array}$ \\
\hline ttti et al., 2010 & $\begin{array}{l}\text { View pain } \\
\text { scenarios }\end{array}$ & FC, ICA & $\begin{array}{l}\text { Within anterior } \\
\text { DMN }\end{array}$ & & 19 & $\begin{array}{l}\downarrow F C \text { from "No Pain" to } \\
\text { "Pain," and the strength } \\
\text { positively correlated with } \\
\text { the subjective post-scan } \\
\text { pain }\end{array}$ \\
\hline
\end{tabular}


Table 1 | Continued

\begin{tabular}{|c|c|c|c|c|c|c|}
\hline Study & Paradigm & Method & $\begin{array}{l}\text { Connectivity } \\
\text { within the DMN }\end{array}$ & $\begin{array}{l}\text { Connectivity between } \\
\text { DMN and other regions }\end{array}$ & $\begin{array}{l}\text { Number } \\
\text { of subjects }\end{array}$ & Results \\
\hline Zaki et al., 2007 & $\begin{array}{l}\text { Experience self } \\
\text { pain, and view } \\
\text { other pain }\end{array}$ & $\begin{array}{l}\mathrm{FC}, \mathrm{PPI}, \\
\text { voxel-wise }\end{array}$ & & $\begin{array}{l}\text { MPFC, PCC-Al, } \\
\text { dACC }\end{array}$ & 19 & $\begin{array}{l}\uparrow F C \text { from self pain task to } \\
\text { other pain task }\end{array}$ \\
\hline $\begin{array}{l}\text { Cheng et al., } \\
2007\end{array}$ & $\begin{array}{l}\text { View pain } \\
\text { scenarios }\end{array}$ & $\begin{array}{l}\text { FC, PPI, } \\
\text { seed-based }\end{array}$ & & MPFC-insula & 28 (14 experts) & $\begin{array}{l}\uparrow \text { negative } \mathrm{FC} \text { in the } \\
\text { experts compared to } \\
\text { control }\end{array}$ \\
\hline $\begin{array}{l}\text { Meyer et al., } \\
2013\end{array}$ & $\begin{array}{l}\text { View social pain } \\
\text { scenarios }\end{array}$ & $\begin{array}{l}\mathrm{FC}, \mathrm{PPI} \\
\text { voxel-wise }\end{array}$ & & $\begin{array}{l}\text { MPFC-AI, } \\
\text { MPFC-dACC }\end{array}$ & 16 & $\begin{array}{l}\uparrow F C \text { for the friend's } \\
\text { exclusion }\end{array}$ \\
\hline Gu et al., 2010 & $\begin{array}{l}\text { View pain } \\
\text { scenarios }\end{array}$ & $\begin{array}{l}\text { FC, PPI, } \\
\text { seed-based }\end{array}$ & & $\begin{array}{l}\text { Superior MPFC- } \\
\text { frontoinsula }\end{array}$ & 18 & $\begin{array}{l}\downarrow F C \text { under the context of } \\
\text { painful stimuli }\end{array}$ \\
\hline Cox et al., 2012 & $\begin{array}{l}\text { Self-report of } \\
\text { empathy }\end{array}$ & FC, seed-based & & $\begin{array}{l}\text { Perigenual } \\
\text { ACC-left } \\
\text { amygdala }\end{array}$ & 38 & $\begin{array}{l}\text { Dominance of affective } \\
\text { empathy was related to } \\
\text { stronger positive FC, } \\
\text { dominance of cognitive } \\
\text { empathy was related to } \\
\text { stronger negative FC }\end{array}$ \\
\hline $\begin{array}{l}\text { Akitsuki and } \\
\text { Decety, } 2009\end{array}$ & $\begin{array}{l}\text { View pain } \\
\text { scenarios }\end{array}$ & $\begin{array}{l}\mathrm{FC}, \mathrm{PPI} \\
\text { voxel-wise }\end{array}$ & & $\begin{array}{l}\text { Medial } \\
\text { OFC-amygdala, } \\
\text { precuneus- } \\
\text { amygdala }\end{array}$ & 26 & $\begin{array}{l}\uparrow F C \text { of medial OFC-left } \\
\text { amygdala, precuneus-left } \\
\text { amygdala during painful } \\
\text { situations caused } \\
\text { intentionally }\end{array}$ \\
\hline \multicolumn{7}{|c|}{ THEORY OF MIND } \\
\hline $\begin{array}{l}\text { Atique et al., } \\
2011\end{array}$ & $\begin{array}{l}\text { Emotion, } \\
\text { intention ToM }\end{array}$ & FC, seed-based & $\begin{array}{l}\text { vMPFC-anterior } \\
\text { TPJ }\end{array}$ & & 24 & $\begin{array}{l}\uparrow F C \text { of vMPFC-anterior } \\
\text { TPJ during emotion } \\
\text { mentalizing }\end{array}$ \\
\hline $\begin{array}{l}\text { Burnett and } \\
\text { Blakemore, } 2009\end{array}$ & $\begin{array}{l}\text { Imagine basic } \\
\text { and social } \\
\text { emotional } \\
\text { experience }\end{array}$ & $\begin{array}{l}\text { FC, PPI, } \\
\text { seed-based, } \\
\text { voxel-wise }\end{array}$ & $\begin{array}{l}\text { Anterior rostral } \\
\text { MPFC-pSTS/TPJ }\end{array}$ & & 28 (10 adults) & $\begin{array}{l}\uparrow F C \text { during social emotion } \\
\text { both in adolescents and } \\
\text { adults, and } \uparrow F C \text { in } \\
\text { adolescents compared to } \\
\text { adults during social } \\
\text { emotion }\end{array}$ \\
\hline $\begin{array}{l}\text { Mason et al., } \\
2008\end{array}$ & Read passages & FC, seed-based & MPFC-TPJ & $\begin{array}{l}\text { Left hemisphere } \\
\text { language } \\
\text { network-ToM } \\
\text { network }\end{array}$ & 36 (10 autistic) & $\begin{array}{l}\downarrow F C \text { between left MPFC } \\
\text { and right TPJ, as well as } \\
\text { left hemisphere language } \\
\text { network and ToM network, } \\
\text { during intentional inference } \\
\text { condition in the autistic } \\
\text { group }\end{array}$ \\
\hline $\begin{array}{l}\text { Baumgartner } \\
\text { et al., } 2012\end{array}$ & $\begin{array}{l}\text { Punish people } \\
\text { for violating } \\
\text { social norms }\end{array}$ & $\begin{array}{l}\text { FC, PPI, } \\
\text { Seed-based }\end{array}$ & dMPFC-left TPJ & & 16 & $\begin{array}{l}\text { Negative correlation } \\
\text { between FC of dMPFC-left } \\
\text { TPJ and third-party } \\
\text { punishment of defecting in } \\
\text { group members }\end{array}$ \\
\hline Das et al., 2012 & $\begin{array}{l}\text { Infer states of } \\
\text { two moving } \\
\text { triangles }\end{array}$ & FC, ICA & & $\begin{array}{l}\text { Posterior } \\
\text { DMN-lateral } \\
\text { fronto-temporal } \\
\text { networks and } \\
\text { insula }\end{array}$ & 45 (23 schizophrenic) & $\downarrow F C$ in schizophrenic \\
\hline
\end{tabular}


Table 1 | Continued

\begin{tabular}{|c|c|c|c|c|c|c|}
\hline Study & Paradigm & Method & $\begin{array}{l}\text { Connectivity } \\
\text { within the DMN }\end{array}$ & $\begin{array}{l}\text { Connectivity between } \\
\text { DMN and other regions }\end{array}$ & $\begin{array}{l}\text { Number } \\
\text { of subjects }\end{array}$ & Results \\
\hline $\begin{array}{l}\text { Herve et al., } \\
2012\end{array}$ & $\begin{array}{l}\text { Comprehend } \\
\text { affective speech }\end{array}$ & FC, seed-based & MPFC-TPJ & $\begin{array}{l}\text { "Medial" } \\
\text { network } \\
\text {-"Language" } \\
\text { network, } \\
\text { amygdala }\end{array}$ & 51 & $\begin{array}{l}\text { Interaction between } \\
\text { language (inferior frontal, } \\
\text { and temporal areas), ToM } \\
\text { (MPFC, TPJ), and emotion } \\
\text { processing network } \\
\text { observed during emotional } \\
\text { speech comprehension }\end{array}$ \\
\hline $\begin{array}{l}\text { Lombardo et al., } \\
2010\end{array}$ & $\begin{array}{l}\text { ToM judgments } \\
\text { about self or a } \\
\text { familiar } \\
\text { non-close other }\end{array}$ & FC, seed-based & & & 33 & $\begin{array}{l}\text { vMPFC, PCC/precuneus, } \\
\text { and TPJ exhibited same FC } \\
\text { patterns during mentalizing } \\
\text { of both self and other }\end{array}$ \\
\hline \multicolumn{7}{|l|}{ MORALITY } \\
\hline Pujol et al., 2012 & $\begin{array}{l}\text { Resting state, } \\
\text { moral dilemma, } \\
\text { stroop task }\end{array}$ & FC, seed-based & MPFC-PCC & & 44 (22 psychopaths) & $\begin{array}{l}\downarrow F C \text { during resting state in } \\
\text { psychopathic group }\end{array}$ \\
\hline Craig et al., 2009 & & DTI & & OFC-amygdala & 27 (18 psychopaths) & $\begin{array}{l}\downarrow F A \text { of the uncinate } \\
\text { fasciculus in psychopaths }\end{array}$ \\
\hline $\begin{array}{l}\text { Marsh et al., } \\
2011\end{array}$ & $\begin{array}{l}\text { Moral judgment } \\
\text { implicit } \\
\text { association }\end{array}$ & FC, seed-based & & $\begin{array}{l}\text { rACC/OFC- } \\
\text { amygdala }\end{array}$ & 28 (14 psychopaths) & $\begin{array}{l}\downarrow \text { FC during task } \\
\text { performance in } \\
\text { psychopaths }\end{array}$ \\
\hline $\begin{array}{l}\text { Decety et al., } \\
2012 a\end{array}$ & $\begin{array}{l}\text { View moral } \\
\text { scenarios }\end{array}$ & $\begin{array}{l}\text { FC, PPI, } \\
\text { seed-based }\end{array}$ & vMPFC-TPJ & $\begin{array}{l}\text { vMPFC- } \\
\text { amygdala }\end{array}$ & 126 & $\begin{array}{l}\uparrow F C \text { of vMPFC-amygdala } \\
\text { with age when viewing } \\
\text { intentional harm, } \uparrow F C \text { of } \\
\text { vMPFC-pSTS/TPJ while } \\
\text { viewing moral actions in } \\
\text { adults compared to } \\
\text { adolescents }\end{array}$ \\
\hline $\begin{array}{l}\text { Verdejo-Garcia } \\
\text { et al., } 2012\end{array}$ & $\begin{array}{l}\text { Resting state, } \\
\text { moral dilemma }\end{array}$ & $\begin{array}{l}\text { FC, seed-based } \\
\text { cross-correlation } \\
\text { analysis }\end{array}$ & & ACC-thalami & 24 (cocaine users) & $\begin{array}{l}\downarrow F C \text { during resting state in } \\
\text { cocaine-dependent } \\
\text { subjects }\end{array}$ \\
\hline $\begin{array}{l}\text { Shannon et al., } \\
2011\end{array}$ & & FC, IDEA & & DMN-PMdr & 202 (107 offenders) & $\begin{array}{l}\text { FC positively correlated } \\
\text { with impulsivity score in } \\
\text { juvenile offenders, while } \\
\text { negatively correlated with } \\
\text { age in typical developing } \\
\text { individuals }\end{array}$ \\
\hline
\end{tabular}

PPI, psychophysiologic interaction analyses; DCM, dynamic causal modeling; ICA, independent component analysis; IDEA, iterative data-driven evolutionary algorithm; FC, functional connectivity; EC, effective connectivity; ASD, autism spectrum disorder; DTI, diffusion tensor imaging; MPFC, medial prefrontal cortex; vMPFC, ventral medial prefrontal cortex; dMPFC, dorsal medial prefrontal cortex; PCC, posterior cingulate cortex; ACC, anterior cingulate cortex; rACC, rostral anterior cingulate cortex; VACC, ventral anterior cingulate cortex; AACC, dorsal anterior cingulate cortex; OFC, orbital frontal cortex; TPJ, temporo-parietal junction area; IPS, intraparietal sulcus; MCC, midcingulate cortex; ParaCC, paracingulate cortex; Al, anterior insula; pSTS, posterior superior temporal sulcus; IFG, inferior frontal gyrus; MTG, middle temporal gyrus; PMdr, dorsolateral premotor cortex; AG, angular gyrus; SFG, superior frontal gyrus; FFA, fusiform face area; rIFGpo, the right pars opercularis of the inferior frontal gyrus; $\mathrm{PHC}$, parahippocampal cortex.

\section{THE DEFAULT MODE NETWORK}

The DMN is an anatomically defined brain system that preferentially activates when individuals are not focused on the external environment (Buckner et al., 2008). Core areas of the DMN include the medial posterior cortex [specifically the posterior cingulate cortex (PCC) and parts of the precuneus], medial prefrontal cortex (MPFC), as well as bilateral inferior parietal lobule (IPL) expanding to posterior temporal areas around the temporo-parietal junction (TPJ). Apart from these core areas, hippocampus and adjacent regions in the medial temporal lobe (MTL) and lateral temporal cortex (LTC) extending toward the temporal pole (TP) are also often reported as part of the DMN 
(Shulman et al., 1997; Buckner et al., 2008; Andrews-Hanna et al., 2010b) (see Figure 1).

The DMN was originally identified in a meta-analysis mapping brain areas that showed increased activity during passive tasks compared to active tasks in block-design positron emission tomography (PET) studies (Shulman et al., 1997). Three kinds of activity patterns within the DMN have been found since then. The first one is consistently decreased activity when subjects engage in goal-directed tasks as compared to control states (Gusnard and Raichle, 2001; Greicius et al., 2003); the second one is the high intrinsic activity during resting states with the eyes closed or visually fixating without engagement in any specific task (Raichle et al., 2001; Greicius et al., 2003; Beckmann et al., 2005); and the last one is the striking overlap between the DMN and regions activated in social cognitive tasks (Schilbach et al., 2008; Eickhoff et al., 2009).

So far, evidence have been found that brain regions within the DMN contribute to specialized functions organized into subsystems that converge on hubs. Buckner et al. (2008) pointed out that the DMN consisted of at least two interacting subsystems: the MTL subsystem containing both the hippocampal formation (HF) and parahippocampal cortex (PHC); and the core MPFC subsystem including the posterior cingulate/retrosplenial cortex (PCC/Rsp), ventral MPFC (vMPFC), and IPL. They proposed that the MTL subsystem was associated with mnemonic processes and activated during successful retrieval of old information, and the MPFC subsystem was activated in tasks requiring participants to engage in self-relevant mental simulations. Using

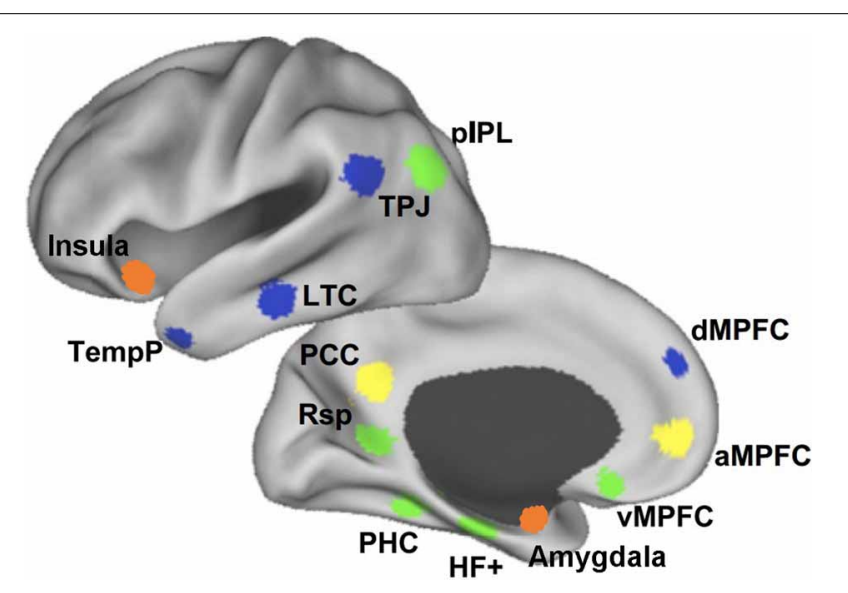

FIGURE 1 | The medial prefrontal cortex (MPFC) plays a key role in the social understanding of others. The subregions of MPFC belong to different subsystems of DMN. At the bottom, the ventral MPFC is in the medial temporal lobe subsystem (green) and its connections with emotion regions are mainly associated with emotion engagement during social interactions. Above, the anterior MPFC is in the cortical midline structures (yellow) and its connections with posterior and anterior cingulate cortex contribute mostly to making self-other distinctions. At the top, the dorsal MPFC (dMPFC) is in the dMPFC subsystem (blue) and its connection with the temporo-parietal junction (TPJ) are primarily related to understanding others' mental states (Andrews-Hanna et al., 2010b). The orange clusters show the anterior insula and amygdala, which contribute greatly in the social understanding of others. memories and associations from past experiences as its building blocks, the DMN participated in constructing self-relevant mental simulations that were exploited by a wide range of cognitive functions including remembering the past, thinking about the future, and conceiving the current viewpoint of others. AndrewsHanna and colleagues further suggested that the DMN consisted of two subsystems that interacted with a common core system (see Figure 1): one was the dorsal MPFC (dMPFC) subsystem comprising the AMPFC, TPJ, LTC, and TP; and the other was the MTL subsystem comprising the HF, PHC, Rsp, vMPFC, and posterior IPL. The dMPFC subsystem was selectively activated when participants considered one's own and others' present mental states, whereas the MTL subsystem showed preferential activity when participants simulated the future using mnemonic imagery-based processes. Both of these two subsystems were strongly correlated with a midline common core system consisting of the anterior MPFC (aMPFC) and PCC, which is usually activated when people make self-relevant affective decisions. The midline core system interacted with the MTL subsystem and the dMPFC subsystem to facilitate the construction of mental models of personally significant events (Andrews-Hanna et al., 2010b).

\section{MEASURING BRAIN CONNECTIVITY IN THE DMN}

An increasing number of researchers are interested in the brain connectivity among the DMN regions and have applied several newly developed approaches and methodologies to DMN studies. In the functional connectivity (FC) approach, researchers compute the statistical interrelation of neurophysiological time series representing temporal changes in different brain regions, and examine the stimulus-dependent and -independent synchronizations and interactions between these regions (Friston, 2005; Menon, 2011). In the effective connectivity (EC) approach, data can be obtained by dynamic causal modeling (DCM), which estimates and judges the negative or positive impacts of one region on another and how such impacts are affected by experimental context (Aertsen et al., 1989; Friston, 2002). Granger causality and other similar methods, unlike the bidirectional functional connectivity, which is a model-free concept, computes the unidirectional EC and emphasizes asymmetric causal interactions between neural systems. Granger causality estimates forward (bottom-up) vs. backward (top-down) connectivity between diverse regions. Nevertheless, it has been criticized for the lack of a biologically-based generative model and likelihood of obtaining pseudo estimated "causality" that is in fact induced by systematic differences across brain areas in hemodynamic lag (Friston, 2009; Smith et al., 2011). Functional and effective connectivity can be studied through both linear techniques (correlation coefficient, coherence) and non-linear techniques (phase synchronization, generalized synchronization) (Stam and van Straaten, 2012). It is worth noting that, negative correlations in brain connectivity analysis, sometimes referred to as anti-correlations, must be cautiously interpreted since they are usually present only after regressing whole-brain signals. This raises a point of controversy: whole-brain normalization leads to a bell-shaped correlation value distribution centered on zero, thereby guaranteeing negative correlations even if such correlations were not initially present in the data (Murphy et al., 2009; van Dijk et al., 2010). 
A brain network can also be defined on the basis of structural connectivity through Magnetic Resonance Imaging (MRI) morphology and Diffusion Tensor Imaging (DTI) tractography in vivo or tracer studies on postmortem tissue. Structural connectivity denotes a network of anatomical links and places constraints on which functional and effective interactions occur in the network (Bullmore and Sporns, 2009; Bressler and Menon, 2010; Menon, 2011).

\section{BRAIN CONNECTIVITY STUDIES ON DMN AND SOCIAL UNDERSTANDING OF OTHERS EMOTION PERCEPTION}

Emotion plays a crucial role in human social cognition. Perceiving and interpreting other people's emotion status is one of the most important steps during social interaction. Traditional studies on the neural mechanism of emotion adopted a locationist approach, which asserted that each basic emotion faculty has its own specialized neural circuitry that is architecturally distinct, inborn, and shared with other animals (Panksepp, 2004). Early neuroimaging results were indeed congruent with this assumption, for example amygdala for fear (Adolphs et al., 1995), insula for disgust (Wicker et al., 2003), orbitofrontal cortex (OFC) for anger (Murphy et al., 2003), and subgenual anterior cingulate cortex (ACC) for sadness (Murphy et al., 2003). However, several recent meta-analyses and reviews favored the psychological constructionist approach, which suggested that a set of interacting brain regions involved in the basic psychological operations of both emotional and nonemotional processing were activated during emotion experience and perception (Lindquist and Barrett, 2012; Lindquist et al., 2012). Yet co-activation of different brain regions does not necessarily mean connectivity between them, so the evidence for the constructionist approach is inconclusive and brain connectivity results would be critical for examining this approach.

Most emotion perception studies using brain connectivity methods revealed changes between the DMN and other brain systems, especially between the prefrontal cortex and amygdala. In a gender discrimination task of angry and neutral faces, Passamonti et al. (2008) confirmed that the interaction between the ventral ACC and amygdala was influenced by the drive to obtain reward, with reduced negative connectivity in high reward-drive participants. The direction of this effect was limited to connection from the ventral ACC to the amygdala but not vice versa. Moreover, in another study, the rostral ACC was negatively coupled with the amygdala in high vs. low conflict resolution trials of a classic emotion Stroop task with fearful and happy faces, and the strength of the connectivity predicted successful conflict resolution (Etkin et al., 2006). Studies also found that the connectivity between different subregions of the MPFC and amygdala may make diverse effects on emotion function. For example, when people did a fear perception task, there was a dorsal-ventral division in ACC modulation of the thalamus-sensory cortex pathway, with a positive modulation of this pathway from dorsal ACC and a negative one from the ventral ACC (Das et al., 2005). In addition, Satterthwaite et al. (2011) demonstrated that the amygdala responded preferentially to threatening (fearful or angry) faces and had increased connectivity during threat trials with the OFC. Moreover, a study also showed that the neuroticism scores of subjects were negatively related to the left amygdala-ACC connectivity, but positively associated with the right amygdala-dorsomedial prefrontal connectivity, when processing negative emotional facial expressions (angry and fearful compared to neutral faces) (Cremers et al., 2010).

Besides the prefrontal cortex and amygdala, functional connectivity changes between other regions were also found in autism patients. For example, in a facial expression identification task, the healthy control group had significantly increased connectivity between the fusiform face area and PCC compared to autism patients (Kleinhans et al., 2008). In another study requiring subjects to passively view emotional facial expressions, typically developing children showed an anticorrelation between the right pars opercularis of the inferior frontal gyrus (rIFGpo) and the DMN, whereas autistic children showed a similar anticorrelated relationship between the rIFGpo and the posterior portion of the DMN, but not the anterior portion of the DMN (vMPFC) (Rudie et al., 2012).

General speaking, the FC in emotion perception studies concentrated on the relation between the vMPFC (including parts of ACC), and other emotion-related areas, mainly the amygdala and insula. The DMN has been theorized to make sensory inputs meaningful as "situated conceptualizations" for distinct emotions, since it reconstitutes past experiences for use in the present (Lindquist and Barrett, 2012; Lindquist et al., 2012). The vMPFC, as part of the DMN, is believed to receive reinforcement expectancy information from emotion learning systems that process the reinforcement provided by specific reinforcers of emotional expressions (Blair, 2007). Thus, the above results from functional connectivity in emotion perception may demonstrate that the vMPFC is indeed associated with successful regulation of human's emotional perception and responses.

\section{EMPATHY}

Empathy can be defined as the process to generate an isomorphic affective state in the self to understand another individual's emotional state or condition while realizing that it is the other who causes this affective state (Decety and Svetlova, 2012; Engen and Singer, 2012). Neuroimaging of empathy is usually acquired by scanning people's brain when they fall into empathic states with various emotions such as disgust, reward, joy, and, particularly, pain (Jabbi et al., 2008; Singer et al., 2009; Bernhardt and Singer, 2012). Researchers proposed that at least three neural systems play vital roles in empathy: the mirror neuron system, the affective empathy system located in the anterior insula (AI) and midcingulate cortex (MCC), and the cognitive empathy system of theory of mind that almost overlaps with the DMN network. The affective empathy system and the cognitive empathy system are linked through the vMPFC (Walter, 2012).

Only a few empathy studies adopted brain connectivity methods to investigate the FC within the DMN, most of which were studying pain. For instance, although temporal correlation analysis demonstrated that the anterior DMN (aDMN) was deactivated in both the "Pain" and "No Pain" conditions compared to the resting-state, the decrease of connectivity was significantly stronger in the "No Pain" than "Pain" condition. In addition, independent component analysis (ICA) demonstrated that higher 
integration of the left medial OFC into the aDMN was associated with higher post-scan pain ratings (Otti et al., 2010).

Most of empathy studies focused on the connection between the DMN (e.g., MPFC) and other regions, especially the insula. When participants watched short videos of other people suffering painful injuries, the brain area of $\mathrm{AMPFC}$ and PCC showed greater connectivity with the dorsal ACC and AI than when participants received noxious thermal stimulation (Zaki et al., 2007). In another study, subjects were asked to view color photographs describing human body parts in painful or non-painful situations and then judge whether the person was suffering from pain or not. Results revealed that the frontoinsular cortex showed decreased FC with the superior MPFC in response to the painful compared to non-painful stimuli ( $\mathrm{Gu}$ et al., 2010). Moreover, observing a friend experiencing social exclusion would trigger greater intensity of FC between the MPFC and both the dorsal ACC and bilateral insula than observing a stranger doing so (Meyer et al., 2013). Furthermore, Cheng et al. (2007) proposed that medical experts who applied painful procedures in their practice could regulate the unpleasant feelings generated by perceiving others in pain through modulating attentional demands. In accord with this hypothesis, experts showed negative FC between the MPFC and AI, whereas the controls showed no significant correlation with the MPFC.

As to the relationship between the amygdala and MPFC in empathy, studies found that the FC pattern between the amygdala and other brain areas was modulated by social context. For instance, the medial OFC and precuneus showed stronger covariation with the left amygdala when the visual stimulus was one person in a painful situation caused by another individual than when the situation was caused by accident (Akitsuki and Decety, 2009). Cox et al. (2012) argued that relative empathic ability (REA), the difference between affective empathy and cognitive empathy, is a useful index for empathy ability. Their results showed that the dominance of affective empathy was associated with stronger FC among social-emotional regions (ventral anterior insula, OFC, amygdala, perigenual ACC), whereas the dominance of cognitive empathy was related to stronger FC among areas implicated in social-cognitive regions (brainstem, STS, ventral anterior insula).

The FC differences found in empathy studies may reflect similar mechanisms as emotion perception, which involve the vMPFC's connection with the amygdala and insula (Akitsuki and Decety, 2009; Otti et al., 2010). Empathy has a deep evolutionary foundation stemming from the phylogenetically ancient practice of parental care, which assists the propagation of genetic legacy to future generations. The motivational systems originally developed to care for one's offspring have gradually been used to facilitate positive relationships between unrelated group members. Ultimately, empathy became a useful means of forming and maintaining strong social bonds between unrelated individuals (Decety et al., 2012b). By enabling human beings to feel the suffering of others, empathy can promote affective interactions and contribute to prosocial behaviors toward other conspecifics, depending on relevant social contexts and social relationships (Decety and Porges, 2011). Thus, it is very important for humans to identify the real protagonist of emotion-the one who causes this affective state. It follows that empathy, to a great extent, is based on emotion perception. Consistent with this line of thought, the region in the frontal cortex that is strongly implicated in both empathy and emotion perception is the aMPFC (Cheng et al., 2007; Otti et al., 2010; Cox et al., 2012; Meyer et al., 2013), which takes charge of the self-other distinction. There are also some other areas connected with the dMPFC (Zaki et al., 2007; Gu et al., 2010), which contribute to the recognition of other humans' mental states.

\section{THEORY OF MIND}

Theory of mind refers to the ability to explain, predict, and interpret another person's behavior by attributing affective and cognitive mental states such as desires, beliefs, intentions and emotions to other people (Amodio and Frith, 2006; Abu-Akel and Shamay-Tsoory, 2011; Krause et al., 2012). The machinery of ToM involves at least three basic processes: representing cognitive and affective mental states, attributing these mental states to others, and finally applying (or deploying) these mental states to correctly comprehend and forecast behavior (Abu-Akel and Shamay-Tsoory, 2011). A number of neuroimaging studies have demonstrated the crucial role of the MPFC in ToM tasks (Northoff and Bermpohl, 2004; Uddin et al., 2007; Qin and Northoff, 2011). Some researchers also declared that ToM was subserved by the posterior DMN (pDMN) regions. For instance, Saxe argued that the right TPJ was vital for representing mental states, particularly false beliefs (Saxe, 2006), and Samson and colleagues proposed that the left TPJ (coupled with the frontal lobes) was crucial for the representation of mental states (Samson et al., 2004). In general, neuroimaging studies have identified a common pattern of brain activation underlying autobiographical memory, ToM, and the DMN (Fair et al., 2008; Spreng et al., 2009; Spreng and Grady, 2010).

Past ToM studies investigating the brain connectivity within the DMN revealed strong connections between the parietal and frontal cortex. For instance, Atique and colleagues compared the different patterns of functional connectivity between inferring another person's emotion (emotion mentalizing) and intention (intention mentalizing) in the DMN. The results revealed a double dissociation, such that a more anterior region of the right and left TPJ was more strongly activated during emotion mentalizing and showed stronger FC with the vMPFC, whereas a more posterior region was more strongly activated during intention mentalizing (Atique et al., 2011). Burnett and Blakemore found that an anterior rostral region of the MPFC (arMPFC) showed greater connectivity with the posterior superior temporal sulcus (pSTS) bordering on the TPJ and anterior temporal cortex during social emotion (such as embarrassment and guilt) than basic emotion, which was in line with the assumption that social emotions require the representation of another's mental states. They also found that the adolescent group possessed stronger connectivity between arMPFC and pSTS/TPJ during social vs. basic emotion than did the adult group (Burnett and Blakemore, 2009). Moreover, Mason et al. (2008) detected that the autism group had lower functional connectivity within the DMN network (between the left medial frontal gyrus and right TPJ) in the intentional inference condition than the control group. In addition, researchers found that when subjects made the decision to 
punish in-group members and out-group members for violating social norms (third-party punishment), the less in-group members were punished, the stronger was the FC between the dMPFC and left TPJ (Baumgartner et al., 2012).

Some other studies explored the connectivity between the DMN network and other regions during ToM processing. For example, in a study asking schizophrenia patients to infer the social interactions of two moving triangles, FC analyses showed that the degree of FC between task-positive (lateral frontotemporal network and insula) and task-negative (medial frontotemporal network and pDMN) regions was significantly reduced in schizophrenia patients as compared to controls (Das et al., 2012). Another study also detected that autistic patients had lower FC between the DMN (the left MPFC and the right TPJ) and a left hemisphere language network (the inferior frontal gyrus and posterior left middle temporal gyrus) in the intentional inference condition than the control group (Mason et al., 2008). Additionally, in a study using an affective speech comprehension task, researchers identified three functional modules with FC analysis, including a "medial" ToM network (the MPFC and TPJ regions), a bilateral "language" network (the inferior frontal and temporal areas), and the bilateral amygdala. The cooperation of these modules was observed during people's emotional speech comprehension, with the left angular gyrus playing a critical role when the medial network and the language network interacted (Herve et al., 2012). Furthermore, Lombardo et al. (2010) found that the vMPFC, PCC/precuneus, and TPJ all exhibited the same FC patterns during mentalizing of both self and others, which indicated that identical neural circuits were implementing processes involved in the mentalizing of both self and others.

To sum up, the main findings of ToM studies focused on the connection between the dMPFC and TPJ (Mason et al., 2008; Burnett and Blakemore, 2009; Baumgartner et al., 2012; Herve et al., 2012), with few studies on the FC between vMPFC (Lombardo et al., 2010; Atique et al., 2011) and aMPFC (Burnett and Blakemore, 2009), as well as some other regions, such as the insula and language network (Das et al., 2012; Herve et al., 2012). Relative to emotion perception and empathy, ToM is considered as a relatively high-level cognitive process (Gallagher and Frith, 2003; Amodio and Frith, 2006). Many species can predict the goals of others, while only humans and perhaps some nonhuman primates can separate one's own mental perspective from that of others (Van Overwalle, 2009; Van Overwalle and Baetens, 2009). The process of ToM critically involves self-projection, since we must imagine ourselves in the same situation as another person and use our own experiences to simulate and understand the mind of that person (Blakemore and Decety, 2001; Spreng et al., 2009; Spreng and Grady, 2010; Spreng and Mar, 2012). Hence, the ToM processes require not only representing current and mnemonic event materials, which mainly depends on the posterior hemisphere of the human brain, but also distinguishing self from others, which is the critical function of the frontal cortex. The involvement of dMPFC in ToM is perhaps due to its responsibility for evaluation and decision-making processes in self- and other-referential processing (van der Meer et al., 2010).

\section{MORALITY}

Psychologists' interest in the moral dimensions of life and thoughts could date back to the dialogs of Plato and Aristotle's ethical treatises. In the recent 20 years, neuroscience has started a new era for moral psychology. Neuroimaging studies have found several brain regions related to morality, such as the ACC (Greene et al., 2004), TPJ (Young et al., 2007, 2011; Young and Saxe, 2008, 2009), vMPFC (Tangney et al., 2007; Zahn et al., 2009; Moll et al., 2011), and dorsolateral prefrontal cortex Greene et al., 2004, 2008. The distributed nature of the moral network led researchers to shift their focus from seeking domain-specific brain regions dedicated to morality to determining the contributions of domain-general processes to morality (Shenhav and Greene, 2010; Young and Dungan, 2011). The existing results show that the moral brain network is closely associated with the DMN (Buckner et al., 2008; Bzdok et al., 2012; Reniers et al., 2012).

Connectivities within the DMN have been found in some morality studies. Decety found that the adult group showed the strongest connectivity between the vMPFC and pSTS/TPJ during viewing of moral actions relative to non-moral actions when compared to other, younger groups (Decety et al., 2012a). Harrison et al. (2008a) compared the FC within the DMN when subjects were resting, judging moral dilemmas, or performing the Stroop task. They found that regions within the DMN, particularly the posterior and anterior cingulated cortex, showed greater correlated activity during the moral dilemma task compared to the resting state. Pujol and colleagues further discovered that, in contrast with control subjects, psychopathic individuals with documented histories of severe criminal offenses showed significantly reduced FC between the medial frontal cortex (aDMN) and posterior brain areas (pDMN) in the resting state (Pujol et al., 2012).

Due to the complexity of morality, researchers are also very interested in the relation between the DMN and other networks, particularly the amygdala. When categorizing illegal and legal behaviors in an implicit association moral judgment task, youths with psychopathic traits displayed reduced FC between the amygdala and the medial OFC compared with healthy controls (Marsh et al., 2011). Decety et al. (2012a) found a positive age-related increase of FC between the vMPFC and amygdala in response to intentional harm. Another study reported significantly reduced fractional anisotropy (FA), an indirect measure of microstructural integrity, in the uncinate fasciculus (white matter connections linking the amygdala and OFC) of psychopaths compared with controls (Craig et al., 2009). Cocaine-dependent subjects have been found to have less resting-state functional connectivity between the ACC, thalamus, insula and the brain stem compared with controls (Verdejo-Garcia et al., 2012). Furthermore, researchers also found that the strength of the coupling between the dorsolateral premotor cortex and the DMN was positively correlated with the impulsivity scores in juvenile offenders but negatively correlated with age in typically developing individuals (Shannon et al., 2011).

Moral judgment is one of the most complex social behaviors. It involves a variety of lower level cognitive processes, such as distinguishing between self and others, integrating social norms, 
computing goal-directed actions, showing empathy to others and inferring the intentions of others (Moll et al., 2008; Bzdok et al., 2012; Feldmanhall et al., 2013). Corresponding complexity has been shown in the above FC results. Moral judgment studies reported FC results that not only involved areas subserving emotion perception, empathy, ToM, but also other regions, such as the FC between the medial OFC and precentral sulcus (Decety et al., 2008), as well as the ACC and thalamus (Verdejo-Garcia et al., 2012). However, neuroimaging studies using brain connectivity methods are still scarce in the field of morality. Given the importance of moral judgment to society, high priority should be given to conducting more studies using the FC approach to further explore the neural mechanisms of morality.

\section{DISCUSSION}

One of the consistent trends revealed in the above studies is that tasks from all the related fields of social understanding of others, from emotion perception to morality, elicit brain connectivity changes from the MPFC (extending to the ACC), a core region of the DMN, to other regions either inside (e.g., TPJ or PCC) or outside (e.g., insula or amygdala) of the DMN. Furthermore, more complex behaviors are subserved by brain regions which are situated higher in the frontal cortex. These results indicate that the MPFC plays a critical role in the social understanding of others, and different parts of MPFC take charge in distinct cognitive processes. According to Andrews-Hanna et al. (2010b), the MPFC can be divided into three subregions that belong to different subsystems of the DMN: the dMPFC in the dMPFC subsystem, the vMPFC in the MTL subsystem and the aMPFC in the midline common core system. The FC results reviewed in the current article provide support for the statements above.

\section{CONNECTIVITY FROM THE vMPFC OF THE MTL SUBSYSTEM}

The vMPFC in the MTL subsystem is crucial in processing emotional features during social cognition. Connectivity changes between the vMPFC and other DMN regions (TPJ) have been found in ToM studies and morality studies. Atique and colleagues found that a more anterior region of the right and left TPJ showed strong FC with the vMPFC during emotion mentalizing (Atique et al., 2011). In contrast, Decety et al. (2012a) found an increase of FC between the vMPFC and PSTS/TPJ while viewing moral actions in adults compared to adolescents. The connection between the vMPFC and TPJ in these two fields can be attributed to the affective aspects of ToM that enables humans to infer emotions.

The dense connections between the vMPFC and emotional regions (e.g., amygdala, insula) means this frontal region can represent and regulate socioemotional states and synthesize a diverse range of information to represent affective mental states (Abu-Akel and Shamay-Tsoory, 2011). In all four fields, particularly emotion perception and empathy, the connectivity changes between the amygdala and vMPFC were repeatedly attested. The detection of connectivity between these two regions, to a certain extent, is consistent with discoveries in animal studies using fear conditioning paradigms which affirm that these regions play a critical role in the process of animal fear conditioning (Maren and Quirk, 2004; Jovanovic and Ressler, 2010; Fiorenza et al., 2012).
Researchers have put forward a fear conditioning neuromechanism model, in which learning the conditioned responses in the central nucleus of the amygdala is modulated by two separate processes. One signals a positive prediction error from the basolateral amygdala, and another signals a negative prediction error from the vMPFC (Moustafa et al., 2013). This model is, in part, similar to the Integrated Emotion Systems (IES) model proposed by Blair (2007), which states that relatively independent emotion learning systems (e.g., the processing of fearful, sad and happy expressions in the amygdala, disgust expressions in the insula, as well as angry expressions in the inferior frontal cortex) input reinforcement expectancy information to the vMPFC while processing reinforcement provided by specific reinforcers of emotional expressions. The vMPFC represents the information and thus allows decision making, including moral decision making. The reduced connectivity between the MPFC and amygdala (Marsh et al., 2008; Glenn, 2011; Motzkin et al., 2011) instead of the insula and inferior frontal cortex in psychopaths relative to controls offers strong confirmation, as their impairments when processing care-based transgressions is thought to depend on the amygdala's role in the association of the transgression with the fear/sadness of the victim. Compared with the IES model, the amygdala-hippocampal-prefrontal interaction model includes the hippocampus, which is also frequently found in emotion related studies using functional connectivity methods (Kensinger and Corkin, 2004; Smith et al., 2006), and takes the effects of environment into account. However, there are still many open questions. For example, what is the actual role of the vMPFC? Does this region only signal a negative prediction error to the central nucleus of the amygdala, as Moustafa states, or does it play a part in successful decision making, as Blair asserts? How do other's emotions influence one's own moral decision?

\section{CONNECTIVITY FROM THE AMPFC OF THE CORTICAL MIDLINE STRUCTURES}

The aMPFC and PCC are part of the core cortical midline structures (CMS) of the DMN, which mostly contributes to the elaboration of the experiential feelings of self (Northoff et al., 2006, 2011; Leech et al., 2011; Pearson et al., 2011; Qin and Northoff, 2011; Denny et al., 2012; Leech and Sharp, 2013). The aMPFC has been proposed to be critical in making self-other distinctions. For example, the aMPFC activates when participants make judgments or remember trait adjectives about themselves compared to other people (e.g., Kelley et al., 2002; D'Argembeau et al., 2005; Heatherton et al., 2006; Mitchell et al., 2006). The above results show the crucial role the aMPFC plays in processes of social behavior, especially empathy. For instance, medical experts who applied painful procedures in their practice showed negative FC between the MPFC and AI, while controls showed no significant correlation with the MPFC (Cheng et al., 2007). It could be interpreted that long-term practice allows the medical experts to regulate the unpleasant feelings through self-other discrimination to identify the real protagonist of pain. In addition, observing a friend experience social exclusion triggers greater intensity of FC between the MPFC and both the dorsal ACC and bilateral insula than observing a stranger doing so (Meyer et al., 2013). This result can be explained by the logic that the concept of friend, 
as compared to stranger, is closer to the self, thus social exclusion of a friend brings about greater FC.

\section{CONNECTIVITY FROM THE dMPFC OF THE dMPFC SUBSYSTEM}

The main results of the reviewed studies with regards to the DMN are the associations between the DMPFC and TPJ in the dMPFC subsystem, which were present not only in ToM (mentalizing) but also in morality studies. Understanding complex social interactions among people who are presumed to be social, interactive, and emotive always involves the processing of selfreflective thoughts and judgments (Buckner et al., 2008). Thus it is not surprising that connections between the TPJ and dMPFC are commonly found in these studies, since these two areas are key regions known to be involved in inferring temporary goals, intentions, desires, and more enduring dispositions of others owing to previous localization results using the mentalizing paradigm (Gallagher and Frith, 2003; Mitchell et al., 2005; Hampton et al., 2008; Steinbeis and Koelsch, 2009; Van Overwalle and Baetens, 2009). For example, studies have shown that functional connectivity between the dMPFC and TPJ increased when healthy participants performed ToM tasks on social properties but decreased when autistic participants did (Mason et al., 2008; Burnett and Blakemore, 2009; Baumgartner et al., 2012).

Several different theories have been proposed to interpret the relationship between the MMPFC and TPJ (as well as other LTC regions such as pSTS). For example, it is suggested that the $\mathrm{dMPFC}$ is associated with the internally-focused process of considering the contents of another person's mind, whereas those temporal regions are related to externally-focused processes that do not require consideration of a target's internal states (Lieberman, 2007). Some researchers have argued that the TPJ is responsible for a domain-general computational mechanism for reorienting attention to the agency (e.g., other individual) and the MPFC is more domain specific for understanding human mental states (Decety and Lamm, 2007). Others have proposed that the TPJ is more specific for the, possibly uniquely, human ability to reason about others' affective and cognitive mental states, and the MPFC is more domain-general (Saxe, 2006). Thus the FC between the TPJ and the MPFC would be an index of either shifting between internally-focused and externally-focused processes or communication between domain-general and domain-specific processing during the understanding of others' mental states.

\section{CONNECTIVITY FROM OTHER REGIONS OF THE DMN}

Besides the MPFC and TPJ, several studies also revealed connectivity changes between the PCC/Precuneus in the CMS and other regions within and outside the DMN (Zaki et al., 2007; Harrison et al., 2008b; Assaf et al., 2010; Weng et al., 2010; Pujol et al., 2012). The PCC appears sensitive not only to explicit emotional engagement, for example, during tasks of emotional word processing and face-perception, but also implicit emotional engagement during self-directed attention or evaluation, as well as autobiographical memory Leech et al., 2011, 2012; Pearson et al., 2011; Leech and Sharp, 2013. Vogt et al. (2006) thus proposed that the PCC may respond to the general emotional content of events, particularly when the nature of processing is self-relevant.
In summary, during tasks from all four social fields, emotion perception, empathy, ToM, and moral judgments, connectivity changes were found between the MPFC and other regions within the DMN (e.g., TPJ, PCC) or outside the DMN (e.g., amygdala, insula). Evidence has shown that the MPFC is closely related to self-referential processing (Northoff et al., 2011; Wagner et al., 2012; Moran et al., 2013). The connectivity changes between the MPFC and other regions further confirm the viewpoint that humans use memories and associations from past experiences as the building blocks for understanding other's emotional and cognitive states. Furthermore, these studies suggest that different parts of the MPFC undertake distinct responsibilities. Specifically, connectivity changes between the emotion regions and vMPFC were repeatedly found in all four fields, particularly emotion perception and empathy; the aMPFC was found to be crucial, especially for empathy; and the associations between the dMPFC and TPJ were usually present in ToM (mentalizing) and morality studies. As social behaviors become more and more complex, the involvement of related regions in the medial frontal cortex gradually increased as well, which may reflect the transition of information processing from automatic to effortful cognitive processes. In consideration of all these findings, we propose that the vMPFC is engaged in identifying self-relevant information and assessing the salience of stimuli (Gusnard et al., 2001; Northoff and Bermpohl, 2004; Northoff et al., 2006); the aMPFC takes charge in making clear self-other distinctions (Andrews-Hanna et al., 2010b), and the dMPFC is involved in the evaluation and decision of whether a certain stimulus is applicable to the self or to another (van der Meer et al., 2010).

In addition to the MPFC regions, social understanding of others also includes cognitive processing for extracting existing storage and perceiving immediate material to represent current events, as well as for identifying and expressing the emotion itself. The former is closely related to the TPJ, which is believed to help in the establishment of a social context for a decision (Carter and Huettel, 2013), whereas the latter is managed by the amygdala, insula and other emotion regions. These three basic processes interact with each other and eventually lead to the formation of complex social behavior.

Reproducibility is a lingering issue with previous studies. For example, Andrews-Hanna and colleagues divided the MPFC into dMPFC, vMPFC, and aMPFC and proposed that they respectively belong to the dMPFC subsystem, MTL subsystem, and common core system (Andrews-Hanna et al., 2010a,b). van der Meer and colleagues further suggested that "the vMPFC is responsible for tagging information relevant for "self," whereas the dMPFC is responsible for evaluation and decision-making processes in selfand other-referential processing" (van der Meer et al., 2010). However, other studies did not emphasize the role of aMPFC, but instead showed that the vMPFC responds more to self, whereas the dMPFC responds more to others (Denny et al., 2012; Wagner et al., 2012). Compared with these studies, the present article specifically highlights the function of self-other distinction in the aMPFC for two main reasons: theoretically, there must be some transition from self to others and the aMPFC anatomically connects the VMPFC and AMPFC; in practice, as we have presented, this area has been repeatedly found to participate in 
the differentiating of self and others. However, to address the divergence and inconsistencies between studies, more brain connectivity methods such as those from graph theory, statistical physics, and non-linear dynamics should be put to use to confirm the relations and differences between the subregions of the MPFC and the DMN. Transcranial magnetic stimulation and transcranial direct-current stimulation should also be considered because they can provide causal evidence to evaluate the above theories.

\section{CONCLUSION AND FUTURE DIRECTIONS}

In this article, we reviewed recent studies on the social understanding of others using brain connectivity methods. We focused on the brain connectivity within and outside the DMN in four different research fields: emotion perception, empathy, ToM, and morality. The reviewed studies suggest that the MPFC plays a key role in the social understanding of others, the subregions of the MPFC contribute differently to this function according to their roles in the different subsystems of the DMN, and more complex behaviors are related to anatomically higher regions in the frontal cortex. Starting from the bottom, the vMPFC in the MTL subsystem and its connection with emotion regions are mainly associated with emotion engagement during social interactions. Above the vMPFC, the aMPFC in the CMS and its connections with the PCC and ACC contribute mostly to making self-other distinctions. At the top, the dMPFC in the dMPFC subsystem and its connection with the TPJ are primarily associated with understanding others' mental states. Besides the MPFC and TPJ, the connectivities of the PCC also show some changes during tasks from the four social fields. These results indicate that the DMN is indispensable in the social understanding of others.

Several points require attention during future development of large-scale brain connectivity studies of social cognition. First of all, interest in brain connectivity arose from the study of brain lesions and neuropsychiatric disorders ranging from epilepsy to autism (Menon, 2011; Shafi et al., 2012). A rich body of literature on neuropsychiatric disorders suggest that abnormalities in the interactions of network components play a vital role in these disorders (Lytton, 2008; Vissers et al., 2012), and damage to specific functional connectivity networks can result in corresponding neuropsychopathy (Seeley et al., 2009). However, compared with lesions and patient studies, there are far fewer studies on healthy human participants applying the methods and theories of brain connectivity, let alone in the field of social cognition. This is a very promising approach for future work.

Secondly, most previous studies exploring the social brain in healthy participants only computed the functional or effective connectivity among regions of interest determined by prior experience or localization tasks, whereas a wide range of brain connectivity methods such as those from graph theory, statistical physics, and non-linear dynamics have been adopted in neuropsychiatric disorders studies (van den Heuvel and Hulshoff Pol, 2010; Menon, 2011; Xia and He, 2011; Stam and van Straaten, 2012; Yu et al., 2012; Griffa et al., 2013). Undoubtedly, these methods should be put to use to confirm the relations and differences between subregions in the MPFC or the DMN and deeply explore the complex social brain network in healthy participants.
Thirdly, so far most brain connectivity studies are conducted with fMRI, a technique based mainly on correlational evidence. However, investigating causality is the main goal of scientific studies, so building causal models accounting for the entire loop of social information processing within and between brains would be a promising future direction (Singer, 2012). Consequently, the methods for studying brain networks could be combined with many other methodologies, such as multivoxel pattern analyses (Carter et al., 2012), transcranial magnetic stimulation/transcranial direct-current stimulation (Young et al., 2010; Carter et al., 2012), genetic-imaging approaches (Glenn, 2011), and pharmacological interventions (Sripada et al., 2012) to explore the neural substrates of various human physiological and psychological states during social interaction.

\section{ACKNOWLEDGMENTS}

We thank Dr. Zheng Li for comments and suggestions. This work was supported by grants from the National Basic Research Program of China (2011CB711000, 2013CB837300), the National Natural Science Foundation of China (NSFC) (31170971, 61210010), and the Major Project of the National Social Science Foundation (12\&ZD228) to Chao Liu and grants from the Major Project of the National Social Science Foundation (13\&ZD155), Humanities and social science projects supported by Ministry of Education (13YJA190007), the Major Research plan of the National Natural Science Foundation of China (913241020,CNLYB1212) to Xiaoqin Mai.

\section{REFERENCES}

Abu-Akel, A., and Shamay-Tsoory, S. (2011). Neuroanatomical and neurochemical bases of theory of mind. Neuropsychologia 49, 2971-2984. doi: 10.1016/j.neuropsychologia.2011.07.012

Adolphs, R., Tranel, D., Damasio, H., and Damasio, A. R. (1995). Fear and the human amygdala. J. Neurosci. 15, 5879-5891.

Aertsen, A. M., Gerstein, G. L., Habib, M. K., and Palm, G. (1989). Dynamics of neuronal firing correlation - modulation of effective connectivity. J. Neurophysiol. 61, 900-917.

Akitsuki, Y., and Decety, J. (2009). Social context and perceived agency affects empathy for pain: an event-related fMRI investigation. Neuroimage 47, 722-734. doi: 10.1016/j.neuroimage.2009.04.091

Amodio, D. M., and Frith, C. D. (2006). Meeting of minds: the medial frontal cortex and social cognition. Nat. Rev. Neurosci. 7, 268-277. doi: 10.1038/ nrn 1884

Andrews-Hanna, J. R., Reidler, J. S., Huang, C., and Buckner, R. L. (2010a). Evidence for the default network's role in spontaneous cognition. J. Neurophysiol. 104, 322-335. doi: 10.1152/jn.00830.2009

Andrews-Hanna, J. R., Reidler, J. S., Sepulcre, J., Poulin, R., and Buckner, R. L. (2010b). Functional-anatomic fractionation of the brain's default network. Neuron 65, 550-562. doi: 10.1016/j.neuron.2010.02.005

Assaf, M., Jagannathan, K., Calhoun, V. D., Miller, L., Stevens, M. C., Sahl, R., et al. (2010). Abnormal functional connectivity of default mode sub-networks in autism spectrum disorder patients. Neuroimage 53, 247-256. doi: 10.1016/ j.neuroimage.2010.05.067

Atique, B., Erb, M., Gharabaghi, A., Grodd, W., and Anders, S. (2011). Task-specific activity and connectivity within the mentalizing network during emotion and intention mentalizing. Neuroimage 55, 1899-1911. doi: 10.1016/j.neuroimage. 2010.12.036

Baumgartner, T., Götte, L., Gügler, R., and Fehr, E. (2012). The mentalizing network orchestrates the impact of parochial altruism on social norm enforcement. Hum. Brain Mapp. 33, 1452-1469. doi: 10.1002/hbm.21298

Beckmann, C. F., Deluca, M., Devlin, J. T., and Smith, S. M. (2005). Investigations into resting-state connectivity using independent component analysis. Philos. Trans. R. Soc. B Biol. Sci. 360, 1001-1013. doi: 10.1098/rstb.2005.1634 
Bernhardt, B. C., and Singer, T. (2012). The neural basis of empathy. Annu. Rev. Neurosci. 35, 1-23. doi: 10.1146/annurev-neuro-062111-150536

Blair, R. J. (2007). The amygdala and ventromedial prefrontal cortex in morality and psychopathy. Trends Cogn. Sci. 11,387-392. doi: 10.1016/j.tics.2007.07.003

Blakemore, S., and Decety, J. (2001). From the perception of action to the understanding of intention. Nat. Rev. Neurosci. 2, 561-567. doi: 10.1038/ 35086023

Bressler, S. L., and Menon, V. (2010). Large-scale brain networks in cognition: emerging methods and principles. Trends Cogn. Sci. 14, 277-290. doi: 10.1016/ j.tics.2010.04.004

Buckner, R. L., Andrews-Hanna, J. R., and Schacter, D. L. (2008). The brain's default network - anatomy, function, and relevance to disease. Ann. N.Y. Acad. Sci. 1124, 1-38. doi: 10.1196/annals.1440.011

Bullmore, E., and Sporns, O. (2009). Complex brain networks: graph theoretical analysis of structural and functional systems. Nat. Rev. Neurosci. 10, 186-198. doi: $10.1038 / \mathrm{nrn} 2575$

Burnett, S., and Blakemore, S. J. (2009). Functional connectivity during a social emotion task in adolescents and in adults. Eur. J. Neurosci. 29, 1294-1301. doi: 10.1111/j.1460-9568.2009.06674.x

Bzdok, D., Schilbach, L., Vogeley, K., Schneider, K., Laird, A. R., Langner, R., et al. (2012). Parsing the neural correlates of moral cognition: ALE meta-analysis on morality, theory of mind, and empathy. Brain Struct. Funct. 217, 783-796. doi: 10.1007/s00429-012-0380-y

Carter, R. M., Bowling, D. L., Reeck, C., and Huettel, S. A. (2012). A distinct role of the temporal-parietal junction in predicting socially guided decisions. Science 337, 109-111. doi: 10.1126/science.1219681

Carter, R. M., and Huettel, S. A. (2013). A nexus model of the temporal-parietal junction. Trends Cogn. Sci. 17, 328-336. doi: 10.1016/j.tics.2013.05.007

Cheng, Y. W., Lin, C. P., Liu, H. L., Hsu, Y. Y., Lims, K. E., Hung, D., et al. (2007). Expertise modulates the perception of pain in others. Curr. Biol. 17, 1708-1713. doi: 10.1016/j.cub.2007.09.020

Cox, C. L., Uddin, L. Q., Di Martino, A., Castellanos, F. X., Milham, M. P., and Kelly, C. (2012). The balance between feeling and knowing: affective and cognitive empathy are reflected in the brain's intrinsic functional dynamics. Soc. Cogn. Affect. Neurosci. 7, 727-737. doi: 10.1093/scan/nsr051

Craig, M. C., Catani, M., Deeley, Q., Latham, R., Daly, E., Kanaan, R., et al. (2009). Altered connections on the road to psychopathy. Mol. Psychiatry 14, 946-953. doi: $10.1038 / \mathrm{mp} .2009 .40$

Cremers, H. R., Demenescu, L. R., Aleman, A., Renken, R., van Tol, M. J., van der Wee, N. J. A., et al. (2010). Neuroticism modulates amygdala-prefrontal connectivity in response to negative emotional facial expressions. Neuroimage 49, 963-970. doi: 10.1016/j.neuroimage.2009.08.023

Das, P., Calhoun, V., and Malhi, G. S. (2012). Mentalizing in male schizophrenia patients is compromised by virtue of dysfunctional connectivity between taskpositive and task-negative networks. Schizophr. Res. 140, 51-58. doi: 10.1016/ j.schres.2012.06.023

Das, P., Kemp, A. H., Liddell, B. J., Brown, K. J., Olivieri, G., Peduto, A., et al. (2005). Pathways for fear perception: modulation of amygdala activity by thalamo-cortical systems. Neuroimage 26, 141-148. doi: 10.1016/j.neuroimage. 2005.01.049

D’Argembeau, A., Collette, F., Van der Linden, M., Laureys, S., Del Fiore, G., Degueldre, C., et al. (2005). Self-referential reflective activity and its relationship with rest: a PET study. Neuroimage 25, 616-624. doi: 10.1016/j.neuroimage. 2004.11.048

Decety, J., and Lamm, C. (2007). The role of the right temporoparietal junction in social interaction: how low-level computational processes contribute to metacognition. Neuroscientist 13, 580-593. doi: 10.1177/1073858407304654

Decety, J., Michalska, K. J., and Akitsuki, Y. (2008). Who caused the pain? An fMRI investigation of empathy and intentionality in children. Neuropsychologia 46, 2607-2614. doi: 10.1016/j.neuropsychologia.2008.05.026

Decety, J., Michalska, K. J., and Kinzler, K. D. (2012a). The contribution of emotion and cognition to moral sensitivity: a neurodevelopmental study. Cereb. Cortex 22, 209-220. doi: 10.1093/cercor/bhr111

Decety, J., Norman, G. J., Berntson, G. G., and Cacioppo, J. T. (2012b). A neurobehavioral evolutionary perspective on the mechanisms underlying empathy. Prog. Neurobiol. 98, 38-48. doi: 10.1016/j.pneurobio.2012.05.001

Decety, J., and Porges, E. C. (2011). Imagining being the agent of actions that carry different moral consequences: an fMRI study. Neuropsychologia 49, 2994-3001. doi: 10.1016/j.neuropsychologia.2011.06.024
Decety, J., and Svetlova, M. (2012). Putting together phylogenetic and ontogenetic perspectives on empathy. Dev. Cogn. Neurosci. 2, 1-24. doi: 10.1016/j.den.2011. 05.003

Denny, B. T., Kober, H., Wager, T. D., and Ochsner, K. N. (2012). A meta-analysis of functional neuroimaging studies of self- and other judgments reveals a spatial gradient for mentalizing in medial prefrontal cortex. J. Cogn. Neurosci. 24 , 1742-1752. doi: 10.1162/jocn_a_00233

Dunbar, R. I. M. (1993). Coevolution of neocortical size, group-size and language in humans. Behav. Brain Sci. 16, 681-694. doi: 10.1017/S0140525X000 32325

Eickhoff, S. B., Laird, A. R., Grefkes, C., Wang, L. E., Zilles, K., and Fox, P. T. (2009). Coordinate-based activation likelihood estimation meta-analysis of neuroimaging data: a random-effects approach based on empirical estimates of spatial uncertainty. Hum. Brain Mapp. 30, 2907-2926. doi: 10.1002/hbm.20718

Engen, H. G., and Singer, T. (2012). Empathy circuits. Curr. Opin. Neurobiol. 23, 275-282. doi: 10.1016/j.conb.2012.11.003

Etkin, A., Egner, T., Peraza, D. M., Kandel, E. R., and Hirsch, J. (2006). Resolving emotional conflict: a role for the rostral anterior cingulate cortex in modulating activity in the amygdala (Vol. 51, pg 871, 2006). Neuron 52, 1121. doi: 10.1016/j.neuron.2006.07.029

Fair, D. A., Cohen, A. L., Dosenbach, N. U. F., Church, J. A., Miezin, F. M., Barch, D. M., et al. (2008). The maturing architecture of the brain's default network. Proc. Natl. Acad. Sci. U.S.A. 105, 4028-4032. doi: 10.1073/pnas.0800376105

Feldmanhall, O., Mobbs, D., and Dalgleish, T. (2013). Deconstructing the brain's moral network: dissociable functionality between the temporoparietal junction and ventro-medial prefrontal cortex. Soc. Cogn. Affect. Neurosci. doi: 10.1093/ scan/nss139. [Epub ahead of print].

Fiorenza, N. G., Rosa, J., Izquierdo, I., and Myskiw, J. C. (2012). Modulation of the extinction of two different fear-motivated tasks in three distinct brain areas. Behav. Brain Res. 232, 210-216. doi: 10.1016/j.bbr.2012.04.015

Friston, K. (2002). Functional integration and inference in the brain. Prog Neurobiol 68, 113-143. doi: 10.1016/S0301-0082(02)00076-X

Friston, K. (2009). Causal modelling and brain connectivity in functional magnetic resonance imaging. PLoS Biol. 7:e33. doi: 10.1371/journal.pbio.1000033

Friston, K. J. (2005). Models of brain function in neuroimaging. Annu. Rev. Psychol. 56, 57-87. doi: 10.1146/annurev.psych.56.091103.070311

Gallagher, H. L., and Frith, C. D. (2003). Functional imaging of 'theory of mind'. Trends Cogn. Sci. 7, 77-83. doi: 10.1016/S1364-6613(02)00025-6

Glenn, A. L. (2011). The other allele: exploring the long allele of the serotonin transporter gene as a potential risk factor for psychopathy: a review of the parallels in findings. Neurosci. Biobehav. Rev. 35, 612-620. doi: 10.1016/j.neubiorev.2010. 07.005

Greene, J. D., Morelli, S. A., Lowenberg, K., Nystrom, L. E., and Cohen, J. D. (2008). Cognitive load selectively interferes with utilitarian moral judgment. Cognition 107, 1144-1154. doi: 10.1016/j.cognition.2007.11.004

Greene, J. D., Nystrom, L. E., Engell, A. D., Darley, J. M., and Cohen, J. D. (2004). The neural bases of cognitive conflict and control in moral judgment. Neuron 44, 389-400. doi: 10.1016/j.neuron.2004.09.027

Greicius, M. D., Krasnow, B., Reiss, A. L., and Menon, V. (2003). Functional connectivity in the resting brain: a network analysis of the default mode hypothesis. Proc. Natl. Acad. Sci. U.S.A. 100, 253-258. doi: 10.1073/pnas.0135058100

Griffa, A., Baumann, P. S., Thiran, J. P., and Hagmann, P. (2013). Structural connectomics in brain diseases. Neuroimage 80, 515-526. doi: 10.1016/j.neuroimage. 2013.04.056

Gu, X., Liu, X., Guise, K. G., Naidich, T. P., Hof, P. R., and Fan, J. (2010). Functional dissociation of the frontoinsular and anterior cingulate cortices in empathy for pain. J. Neurosci. 30, 3739-3744. doi: 10.1523/JNEUROSCI.4844-09.2010

Gusnard, D. A., Akbudak, E., Shulman, G. L., and Raichle, M. E. (2001). Medial prefrontal cortex and self-referential mental activity: relation to a default mode of brain function. Proc. Natl. Acad. Sci. U.S.A. 98, 4259-4264. doi: 10.1073/pnas. 071043098

Gusnard, D. A., and Raichle, M. E. (2001). Searching for a baseline: functional imaging and the resting human brain. Nat. Rev. Neurosci. 2, 685-694. doi: $10.1038 / 35094500$

Hampton, A. N., Bossaerts, P., and O’Doherty, J. P. (2008). Neural correlates of mentalizing-related computations during strategic interactions in humans. Proc. Natl. Acad. Sci. U.S.A. 105, 6741-6746. doi: 10.1073/pnas.0711099105

Harrison, B. J., Pujol, J., Lopez-Sola, M., Hernandez-Ribas, R., Deus, J., Ortiz, H., et al. (2008a). Consistency and functional specialization in the default mode 
brain network. Proc. Natl. Acad. Sci. U.S.A. 105, 9781-9786. doi: 10.1073/pnas. 0711791105

Harrison, B. J., Pujol, J., Ortiz, H., Fornito, A., Pantelis, C., and Yücel, M. (2008b). Modulation of brain resting-state networks by sad mood induction. PLoS ONE 3:e1794. doi: 10.1371/journal.pone.0001794

Heatherton, T. F., Wyland, C. L., Macrae, C. N., Demos, K. E., Denny, B. T., and Kelley, W. M. (2006). Medial prefrontal activity differentiates self from close others. Soc. Cogn. Affect. Neurosci. 1, 18-25. doi: 10.1093/scan/nsl001

Herve, P. Y., Razafimandimby, A., Vigneau, M., Mazoyer, B., and Tzourio-Mazoyer, N. (2012). Disentangling the brain networks supporting affective speech comprehension. Neuroimage 61, 1255-1267. doi: 10.1016/j.neuroimage.2012.03.073

Jabbi, M., Bastiaansen, J., and Keysers, C. (2008). A common anterior insula representation of disgust observation, experience and imagination shows divergent functional connectivity pathways. PLoS ONE 3:e2939. doi: 10.1371/journal.pone. 0002939

Jovanovic, T., and Ressler, K. J. (2010). How the neurocircuitry and genetics of fear inhibition may inform our understanding of PTSD. Am. J. Psychiatry 167, 648-662. doi: 10.1176/appi.ajp.2009.09071074

Kelley, W. M., Macrae, C. N., Wyland, C. L., Caglar, S., Inati, S., and Heatherton, T. F. (2002). Finding the self? An event-related fMRI study. J. Cogn. Neurosci. 14 785-794. doi: 10.1162/08989290260138672

Kensinger, E. A., and Corkin, S. (2004). Two routes to emotional memory: distinct neural processes for valence and arousal. Proc. Natl. Acad. Sci. U.S.A. 101, 3310-3315. doi: 10.1073/pnas.0306408101

Kleinhans, N. M., Richards, T., Sterling, L., Stegbauer, K. C., Mahurin, R., Johnson, L. C., et al. (2008). Abnormal functional connectivity in autism spectrum disorders during face processing. Brain 131, 1000-1012. doi: 10.1093/brain/awm334

Krause, L., Enticott, P. G., Zangen, A., and Fitzgerald, P. B. (2012). The role of medial prefrontal cortex in theory of mind: a deep rTMS study. Behav. Brain Res. 228, 87-90. doi: 10.1016/j.bbr.2011.11.037

Laird, A. R., Fox, P. M., Eickhoff, S. B., Turner, J. A., Ray, K. L., McKay, D. R., et al. (2011). Behavioral interpretations of intrinsic connectivity networks. J. Cogn. Neurosci. 23, 4022-4037. doi: 10.1162/jocn_a_00077

Leech, R., Braga, R., and Sharp, D. J. (2012). Echoes of the brain within the posterior cingulate cortex. J. Neurosci. 32, 215-222. doi: 10.1523/JNEUROSCI.368911.2012

Leech, R., Kamourieh, S., Beckmann, C. F., and Sharp, D. J. (2011). Fractionating the default mode network: distinct contributions of the ventral and dorsal posterior cingulate cortex to cognitive control. J. Neurosci. 31, 3217-3224. doi: 10.1523/JNEUROSCI.5626-10.2011

Leech, R., and Sharp, D. J. (2013). The role of the posterior cingulate cortex in cognition and disease. Brain 137, 12-32. doi: 10.1093/brain/awt162

Lieberman, M. D. (2007). Social cognitive neuroscience: a review of core processes. Annu. Rev. Psychol. 58, 259-289. doi: 10.1146/annurev.psych.58.110405.085654

Lindquist, K. A., and Barrett, L. F. (2012). A functional architecture of the human brain: emerging insights from the science of emotion. Trends Cogn. Sci. 16, 533-540. doi: 10.1016/j.tics.2012.09.005

Lindquist, K. A., Wager, T. D., Kober, H., Bliss-Moreau, E., and Barrett, L. F. (2012). The brain basis of emotion: a meta-analytic review. Behav. Brain Sci. 35, 121-143. doi: 10.1017/S0140525X11000446

Lombardo, M. V., Chakrabarti, B., Bullmore, E. T., Wheelwright, S. J., Sadek, S. A., Suckling, J., et al. (2010). Shared neural circuits for mentalizing about the self and others. J. Cogn. Neurosci. 22, 1623-1635. doi: 10.1162/jocn.2009.21287

Lytton, W. W. (2008). Computer modelling of epilepsy. Nat. Rev. Neurosci. 9, 626-637. doi: 10.1038/nrn2416

Maren, S., and Quirk, G. J. (2004). Neuronal signalling of fear memory. Nat. Rev. Neurosci. 5, 844-852. doi: 10.1038/nrn1535

Mars, R. B., Neubert, F. X., Noonan, M. P., Sallet, J., Toni, I., and Rushworth, M. F. (2012). On the relationship between the "default mode network" and the "social brain." Front. Hum. Neurosci. 6:189. doi: 10.3389/fnhum.2012.00189

Marsh, A. A., Finger, E. C., Fowler, K. A., Jurkowitz, I. T., Schechter, J. C., Yu, H. H., et al. (2011). Reduced amygdala-orbitofrontal connectivity during moral judgments in youths with disruptive behavior disorders and psychopathic traits. Psychiatry Res. 194, 279-286. doi: 10.1016/j.pscychresns.2011. 07.008

Marsh, A. A., Finger, E. C., Mitchell, D. G. V., Reid, M. E., Sims, C., Kosson, D. S., et al. (2008). Reduced amygdala response to fearful expressions in children and adolescents with callous-unemotional traits and disruptive behavior disorders. Am. J. Psychiatry 165, 712-720. doi: 10.1176/appi.ajp.2007.07071145
Mason, R. A., Williams, D. L., Kana, R. K., Minshew, N., and Just, M. A. (2008). Theory of Mind disruption and recruitment of the right hemisphere during narrative comprehension in autism. Neuropsychologia 46, 269-280. doi: 10.1016/ j.neuropsychologia.2007.07.018

Menon, V. (2011). Large-scale brain networks and psychopathology: a unifying triple network model. Trends Cogn. Sci. 15, 483-506. doi: 10.1016/j.tics.2011. 08.003

Meyer, M. L., Masten, C. L., Ma, Y., Wang, C., Shi, Z., Eisenberger, N. I., et al. (2013). Empathy for the social suffering of friends and strangers recruits distinct patterns of brain activation. Soc. Cogn. Affect. Neurosci. 8, 446-454. doi: 10.1093/scan/nss019

Mitchell, J. P., Macrae, C. N., and Banaji, M. R. (2005). Forming impressions of people versus inanimate objects: social-cognitive processing in the medial prefrontal cortex. Neuroimage 26, 251-257. doi: 10.1016/j.neuroimage.2005. 01.031

Mitchell, J. P., Macrae, C. N., and Banaji, M. R. (2006). Dissociable medial prefrontal contributions to judgments of similar and dissimilar others. Neuron 50 , 655-663. doi: 10.1016/j.neuron.2006.03.040

Moll, J., De Oliveira-Souza, R., and Zahn, R. (2008). The neural basis of moral cognition: sentiments, concepts, and values. Ann. N.Y. Acad. Sci. 1124, 161-180. doi: 10.1196/annals.1440.005

Moll, J., Zahn, R., De Oliveira-Souza, R., Bramati, I. E., Krueger, F., Tura, B., et al. (2011). Impairment of prosocial sentiments is associated with frontopolar and septal damage in frontotemporal dementia. Neuroimage 54, 1735-1742. doi: 10.1016/j.neuroimage.2010.08.026

Moran, J. M., Kelley, W. M., and Heatherton, T. F. (2013). What can the organization of the brain's default mode network tell us about self-knowledge? Front. Hum. Neurosci. 7:391. doi: 10.3389/fnhum.2013.00391

Motzkin, J. C., Newman, J. P., Kiehl, K. A., and Koenigs, M. (2011). Reduced prefrontal connectivity in psychopathy. J. Neurosci. 31, 17348-17357. doi: 10.1523/JNEUROSCI.4215-11.2011

Moustafa, A. A., Gilbertson, M. W., Orr, S. P., Herzallah, M. M., Servatius, R. J., and Myers, C. E. (2013). A model of amygdala-hippocampal-prefrontal interaction in fear conditioning and extinction in animals. Brain Cogn. 81, 29-43. doi: 10.1016/j.bandc.2012.10.005

Murphy, F. C., Nimmo-Smith, I., and Lawrence, A. D. (2003). Functional neuroanatomy of emotions: a meta-analysis. Cogn. Affect. Behav. Neurosci. 3, 207-233. doi: 10.3758/CABN.3.3.207

Murphy, K., Birn, R. M., Handwerker, D. A., Jones, T. B., and Bandettini, P. A. (2009). The impact of global signal regression on resting state correlations: are anti-correlated networks introduced? Neuroimage 44, 893-905. doi: 10.1016/j.neuroimage.2008.09.036

Northoff, G., and Bermpohl, F. (2004). Cortical midline structures and the self. Trends Cogn. Sci. 8, 102-107. doi: 10.1016/j.tics.2004.01.004

Northoff, G., Heinzel, A., Greck, M., Bennpohl, F., Dobrowolny, H., and Panksepp, J. (2006). Self-referential processing in our brain - a meta-analysis of imaging studies on the self. Neuroimage 31, 440-457. doi: 10.1016/j.neuroimage.2005. 12.002

Northoff, G., Qin, P. M., and Feinberg, T. E. (2011). Brain imaging of the self conceptual, anatomical and methodological issues. Conscious. Cogn. 20, 52-63. doi: 10.1016/j.concog.2010.09.011

Otti, A., Guendel, H., Läer, L., Wohlschlaeger, A. M., Lane, R. D., Decety, J., et al. (2010). I know the pain you feel-how the human brain's default mode predicts our resonance to another's suffering. Neuroscience 169, 143-148. doi: 10.1016/j.neuroscience.2010.04.072

Panksepp, J. (2004). Affective Neuroscience: The Foundations of Human and Animal Emotions. New York, NY: Oxford University Press.

Passamonti, L., Rowe, J. B., Ewbank, M., Hampshire, A., Keane, J., and Calder, A. J. (2008). Connectivity from the ventral anterior cingulate to the amygdala is modulated by appetitive motivation in response to facial signals of aggression. Neuroimage 43, 562-570. doi: 10.1016/j.neuroimage.2008. 07.045

Pearson, J. M., Heilbronner, S. R., Barack, D. L., Hayden, B. Y., and Platt, M. L. (2011). Posterior cingulate cortex: adapting behavior to a changing world. Trends Cogn. Sci. 15, 143-151. doi: 10.1016/j.tics.2011.02.002

Pujol, J., Batalla, I., Contreras-Rodriguez, O., Harrison, B. J., Pera, V., HernandezRibas, R., et al. (2012). Breakdown in the brain network subserving moral judgment in criminal psychopathy. Soc. Cogn. Affect. Neurosci. 7, 917-923. doi: 10.1093/scan/nsr075 
Qin, P., and Northoff, G. (2011). How is our self related to midline regions and the default-mode network? Neuroimage 57, 1221-1233. doi: 10.1016/j.neuroimage. 2011.05.028

Raichle, M. E., MacLeod, A. M., Snyder, A. Z., Powers, W. J., Gusnard, D. A., and Shulman, G. L. (2001). A default mode of brain function. Proc. Natl. Acad. Sci. U.S.A. 98, 676-682. doi: 10.1073/pnas.98.2.676

Reniers, R. L., Corcoran, R., Völlm, B. A., Mashru, A., Howard, R., and Liddle, P. F. (2012). Moral decision-making, ToM, empathy and the default mode network. Biol. Psychol. 90, 202-210. doi: 10.1016/j.biopsycho.2012.03.009

Rudie, J. D., Shehzad, Z., Hernandez, L. M., Colich, N. L., Bookheimer, S. Y., Iacoboni, M., et al. (2012). Reduced functional integration and segregation of distributed neural systems underlying social and emotional information processing in autism spectrum disorders. Cereb. Cortex 22, 1025-1037. doi: 10.1093/cercor/bhr171

Samson, D., Apperly, I. A., Chiavarino, C., and Humphreys, G. W. (2004). Left temporoparietal junction is necessary for representing someone else's belief. Nat. Neurosci. 7, 499-500. doi: 10.1038/nn1223

Satterthwaite, T. D., Wolf, D. H., Pinkham, A. E., Ruparel, K., Elliott, M. A., Valdez, J. N., et al. (2011). Opposing amygdala and ventral striatum connectivity during emotion identification. Brain Cogn. 76, 353-363. doi: 10.1016/j.bandc.2011. 04.005

Saxe, R. (2006). Uniquely human social cognition. Curr. Opin. Neurobiol. 16, 235-239. doi: 10.1016/j.conb.2006.03.001

Schilbach, L., Eickhoff, S. B., Rska-Jagiela, A. R., Fink, G. R., and Vogeley, K. (2008). Minds at rest? Social cognition as the default mode of cognizing and its putative relationship to the "default system" of the brain. Conscious. Cogn. 17, 457-467. doi: 10.1016/j.concog.2008.03.013

Seeley, W. W., Crawford, R. K., Zhou, J., Miller, B. L., and Greicius, M. D. (2009). Neurodegenerative diseases target large-scale human brain networks. Neuron 62, 42-52. doi: 10.1016/j.neuron.2009.03.024

Shafi, M. M., Westover, M. B., Fox, M. D., and Pascual-Leone, A. (2012). Exploration and modulation of brain network interactions with noninvasive brain stimulation in combination with neuroimaging. Eur. J. Neurosci. 35, 805-825. doi: 10.1111/j.1460-9568.2012.08035.x

Shannon, B. J., Raichle, M. E., Snyder, A. Z., Fair, D. A., Mills, K. L., Zhang, D. Y., et al. (2011). Premotor functional connectivity predicts impulsivity in juvenile offenders. Proc. Natl. Acad. Sci. U.S.A. 108, 11241-11245. doi: $10.1073 /$ pnas. 1108241108

Shenhav, A., and Greene, J. D. (2010). Moral judgments recruit domain-general valuation mechanisms to integrate representations of probability and magnitude. Neuron 67, 667-677. doi: 10.1016/j.neuron.2010.07.020

Shulman, G. L., Fiez, J. A., Corbetta, M., Buckner, R. L., Miezin, F. M., Raichle, M. E., et al. (1997). Common blood flow changes across visual tasks.2. Decreases in cerebral cortex. J. Cogn. Neurosci. 9, 648-663. doi: 10.1162/jocn.1997.9.5.648

Singer, T. (2012). The past, present and future of social neuroscience: a European perspective. Neuroimage 61, 437-449. doi: 10.1016/j.neuroimage.2012. 01.109

Singer, T., Critchley, H. D., and Preuschoff, K. (2009). A common role of insula in feelings, empathy and uncertainty. Trends Cogn. Sci. 13, 334-340. doi: 10.1016/j.tics.2009.05.001

Smith, A. P. R., Stephan, K. E., Rugg, M. D., and Dolan, R. J. (2006). Task and content modulate amygdala-hippocampal connectivity in emotional retrieval. Neuron 49, 631-638. doi: 10.1016/j.neuron.2005.12.025

Smith, S. M., Miller, K. L., Salimi-Khorshidi, G., Webster, M., Beckmann, C. F., Nichols, T. E., et al. (2011). Network modelling methods for FMRI. Neuroimage 54, 875-891. doi: 10.1016/j.neuroimage.2010.08.063

Spreng, R. N., and Grady, C. L. (2010). Patterns of brain activity supporting autobiographical memory, prospection, and theory of mind, and their relationship to the default mode network. J. Cogn. Neurosci. 22, 1112-1123. doi: 10.1162/jocn.2009.21282

Spreng, R. N., and Mar, R. A. (2012). I remember you: a role for memory in social cognition and the functional neuroanatomy of their interaction. Brain Res. 1428, 43-50. doi: 10.1016/j.brainres.2010.12.024

Spreng, R. N., Mar, R. A., and Kim, A. S. N. (2009). The common neural basis of autobiographical memory, prospection, navigation, theory of mind, and the default mode: a quantitative meta-analysis. J. Cogn. Neurosci. 21, 489-510. doi: 10.1162/jocn.2008.21029

Sripada, C. S., Phan, K. L., Labuschagne, I., Welsh, R., Nathan, P. J., and Wood, A. G. (2012). Oxytocin enhances resting-state connectivity between amygdala and medial frontal cortex. Int. J. Neuropsychopharmacol 16, 1-6. doi: 10.1017/ S1461145712000533

Stam, C. J., and van Straaten, E. C. W. (2012). The organization of physiological brain networks. Clin. Neurophysiol. 123, 1067-1087. doi: 10.1016/j.clinph.2012. 01.011

Steinbeis, N., and Koelsch, S. (2009). Understanding the intentions behind manmade products elicits neural activity in areas dedicated to mental state attribution. Cereb. Cortex 19, 619-623. doi: 10.1093/cercor/bhn110

Tangney, J. P., Stuewig, J., and Mashek, D. J. (2007). Moral emotions and moral behavior. Annu. Rev. Psychol. 58, 345-372. doi: 10.1146/annurev.psych.56.091 103.070145

Uddin, L. Q., Iacoboni, M., Lange, C., and Keenan, J. P. (2007). The self and social cognition: the role of cortical midline structures and mirror neurons. Trends Cogn. Sci. 11, 153-157. doi: 10.1016/j.tics.2007.01.001

van den Heuvel, M. P., and Hulshoff Pol, H. E. (2010). Exploring the brain network: a review on resting-state fMRI functional connectivity. Eur. Neuropsychopharmacol. 20, 519-534. doi: 10.1016/j.euroneuro.2010.03.008

van der Meer, L., Costafreda, S., Aleman, A., and David, A. S. (2010). Self-reflection and the brain: a theoretical review and meta-analysis of neuroimaging studies with implications for schizophrenia. Neurosci. Biobehav. Rev. 34, 935-946. doi: 10.1016/j.neubiorev.2009.12.004

van Dijk, K. R., Hedden, T., Venkataraman, A., Evans, K. C., Lazar, S. W., and Buckner, R. L. (2010). Intrinsic functional connectivity as a tool for human connectomics: theory, properties, and optimization. J. Neurophysiol. 103, 297-321. doi: 10.1152/jn.00783.2009

Van Overwalle, F. (2009). Social cognition and the brain: a meta-analysis. Hum. Brain Mapp. 30, 829-858. doi: 10.1002/hbm.20547

Van Overwalle, F., and Baetens, K. (2009). Understanding others' actions and goals by mirror and mentalizing systems: a meta-analysis. Neuroimage 48, 564-584. doi: 10.1016/j.neuroimage.2009.06.009

Verdejo-Garcia, A., Contreras-Rodríguez, O., Fonseca, F., Cuenca, A., Soriano-Mas, C., Rodriguez, J., et al. (2012). Functional alteration in frontolimbic systems relevant to moral judgment in cocaine-dependent subjects. Addict. Biol. doi: 10.1111/j.1369-1600.2012.00472.x. [Epub ahead of print].

Vissers, M. E., Cohen, M. X., and Geurts, H. M. (2012). Brain connectivity and high functioning autism: a promising path of research that needs refined models, methodological convergence, and stronger behavioral links. Neurosci. Biobehav. Rev. 36, 604-625. doi: 10.1016/j.neubiorev.2011.09.003

Vogt, B. A., Vogt, L., and Laureys, S. (2006). Cytology and functionally correlated circuits of human posterior cingulate areas. Neuroimage 29, 452-466. doi: 10.1016/j.neuroimage.2005.07.048

Wagner, D. D., Haxby, J. V., and Heatherton, T. F. (2012). The representation of self and person knowledge in the medial prefrontal cortex. Wiley Interdiscip. Rev. Cogn. Sci. 3, 451-470. doi: 10.1002/wcs.1183

Walter, H. (2012). Social cognitive neuroscience of empathy: concepts, circuits, and genes. Emot. Rev. 4, 9-17. doi: 10.1177/1754073911421379

Weng, S. J., Wiggins, J. L., Peltier, S. J., Carrasco, M., Risi, S., Lord, C., et al. (2010). Alterations of resting state functional connectivity in the default network in adolescents with autism spectrum disorders. Brain Res. 1313, 202-214. doi: 10.1016/j.brainres.2009.11.057

Wicker, B., Keysers, C., Plailly, J., Royet, J. P., Gallese, V., and Rizzolatti, G. (2003). Both of us disgusted in My insula: the common neural basis of seeing and feeling disgust. Neuron 40, 655-664. doi: 10.1016/S0896-6273(03) 00679-2

Xia, M., and He, Y. (2011). Magnetic resonance imaging and graph theoretical analysis of complex brain networks in neuropsychiatric disorders. Brain Connect. 1, 349-365. doi: 10.1089/brain.2011.0062

Young, L., Camprodon, J. A., Hauser, M., Pascual-Leone, A., and Saxe, R. (2010) Disruption of the right temporoparietal junction with transcranial magnetic stimulation reduces the role of beliefs in moral judgments. Proc. Natl. Acad. Sci. U.S.A. 107, 6753-6758. doi: 10.1073/pnas.0914826107

Young, L., Cushman, F., Hauser, M., and Saxe, R. (2007). The neural basis of the interaction between theory of mind and moral judgment. Proc. Natl. Acad. Sci. U.S.A. 104, 8235-8240. doi: 10.1073/pnas.0701408104

Young, L., and Dungan, J. (2011). Where in the brain is morality? Everywhere and maybe nowhere. Soc. Neurosci. 7, 1-10. doi: 10.1080/17470919.2011.569146

Young, L., and Saxe, R. (2008). The neural basis of belief encoding and integration in moral judgment. Neuroimage 40, 1912-1920. doi: 10.1016/j.neuroimage. 2008.01.057 
Young, L., and Saxe, R. (2009). An FMRI investigation of spontaneous mental state inference for moral judgment. J. Cogn. Neurosci. 21, 1396-1405. doi: 10.1162/ jocn.2009.21137

Young, L., Scholz, J., and Saxe, R. (2011). Neural evidence for "intuitive prosecution": the use of mental state information for negative moral verdicts. Soc. Neurosci. 6, 302-315. doi: 10.1080/17470919.2010.529712

Yu, Q. B., Allen, E. A., Sui, J., Arbabshirani, M. R., Pearlson, G., and Calhoun, V. D. (2012). Brain connectivity networks in schizophrenia underlying resting state functional magnetic resonance imaging. Curr. Top. Med. Chem. 12, 2415-2425. doi: 10.2174/156802612805289890

Zahn, R., Moll, J., Paiva, M., Garrido, G., Krueger, F., Huey, E. D., et al. (2009). The neural basis of human social values: evidence from functional MRI. Cereb. Cortex 19, 276-283. doi: 10.1093/cercor/bhn080

Zaki, J., Ochsner, K. N., Hanellin, J., Wager, T. D., and Mackey, S. C. (2007). Different circuits for different pain: patterns of functional connectivity reveal distinct networks for processing pain in self and others. Soc. Neurosci. 2, 276-291. doi: 10.1080/17470910701401973
Conflict of Interest Statement: The authors declare that the research was conducted in the absence of any commercial or financial relationships that could be construed as a potential conflict of interest.

Received: 01 June 2013; accepted: 29 January 2014; published online: 24 February 2014.

Citation: Li W, Mai X and Liu C (2014) The default mode network and social understanding of others: what do brain connectivity studies tell us. Front. Hum. Neurosci. 8:74. doi: 10.3389/fnhum.2014.00074

This article was submitted to the journal Frontiers in Human Neuroscience.

Copyright (C) $2014 \mathrm{Li}, \mathrm{Mai}$ and Liu. This is an open-access article distributed under the terms of the Creative Commons Attribution License (CC BY). The use, distribution or reproduction in other forums is permitted, provided the original author(s) or licensor are credited and that the original publication in this journal is cited, in accordance with accepted academic practice. No use, distribution or reproduction is permitted which does not comply with these terms. 